\title{
THE RESULTS AND COMPLICATIONS OF HYPOTHERMIC PERFUSION
}

\author{
BY \\ P. J. MOLLOY* \\ From the Thoracic Surgical Unit, Guy's Hospital, London
}

(RECEIVED FOR PUBLICATION OCTOBER, 1961)

From September, 1959, to July, 1961, 194 patients have been treated by open heart surgery at Guy's Hospital requiring the support of extracorporeal circulation. This report is to indicate briefly the nature of the cases, mortality rates, and complications arising from hypothermic perfusion as practised in this hospital. The technique of perfusion is discussed elsewhere in this issue (Molloy and Lindfield, 1961).

\section{RESULTS}

The diagnoses and results of treatment are indicated in Table I and compared with the results in the last 100 cases. Congenital lesions have a good prognosis surgically, but acquired lesions bear a heavy mortality.

The age, sex distribution, and the range of size of patient and length of perfusion are indicated in Table II. It will be noted that many of the patients with Fallot's tetralogy in this series have previously had a first-stage operation for direct relief of the right ventricular outflow tract obstruction (Brock, 1948, 1959a, 1959b) because they had been thought unsuitable for a single-stage total corrective procedure. Cases of aortic stenosis have been mostly calcific, and the mortality emphasizes the need for early diagnosis and treatment of these cases, especially those of congenital origin.

\section{Complications}

Post-operative complications have occurred and have been concerned with the following:

Chest.-Some patients have developed a congestive syndrome post-operatively similar to that described by Baer and Osborn (1960). This responds to humidification and physiotherapy, but in some cases tracheostomy has been necessary to deal with sticky secretions and carbon dioxide retention. Distension of the lungs during perfu-

*Leverhulme research fellow. sion with a mixture of $80 \%$ helium in oxygen at low pressure is thought to reduce the incidence of this complication as is the avoidance of atropine at the end of the operation. Evidence presented by Comroe (1961) would indicate that a secreted surface-active material lining the alveoli may be reduced during perfusion, causing a rise in alveolar surface tension from 2 to 10 dynes per $\mathrm{cm}$. to 20 dynes per $\mathrm{cm}$., thus facilitating alveolar collapse.

Cerebral.-These have been few. One boy had an episode of fits and spasticity on sitting up after normal recovery but recovered after two days. An air embolus was thought to have shifted with posture. Two patients with aortic stenosis who died in coma after several days on the respirator were shown at necropsy to have calcific emboli in the brain. Cerebral oedema was shown in three children who developed heart block after closure of a ventricular septal defect, but it is difficult to apportion blame either to inadequate perfusion or to cardiac failure with high intracranial venous pressure.

Renal.-Several patients have developed the condition of a rising blood urea level, normal electrolytes, normal 24-hour excretion of urea and electrolytes associated with a urine of fixed specific gravity (1010-1014) passed in quantities of less than $1,000 \mathrm{ml} . / 24$ hours. Investigations are proceeding to elucidate this condition, which resembles the early stage of acute tubular necrosis.

Three patients have become frankly oliguric with rising blood urea and serum potassium levels. Two recovered with dialysis. In each case haemolysis occurring early in perfusion associated with a period of post-operative hypotension was adjudged the cause. The haemolysis was thought due to minor incompatibilities between bottles of blood used for priming although all were demonstrated compatible with the patient, but the presence of detergents or haemolytic agents in 
TABLE I

DIAGNOSES AND MORTALITY IN 194 PATIENTS SUBMITTED TO OPEN HEART SURGERY UNDER HYPOTHERM IC BYPASS AND COMPARISON WITH LAST 100 CASES

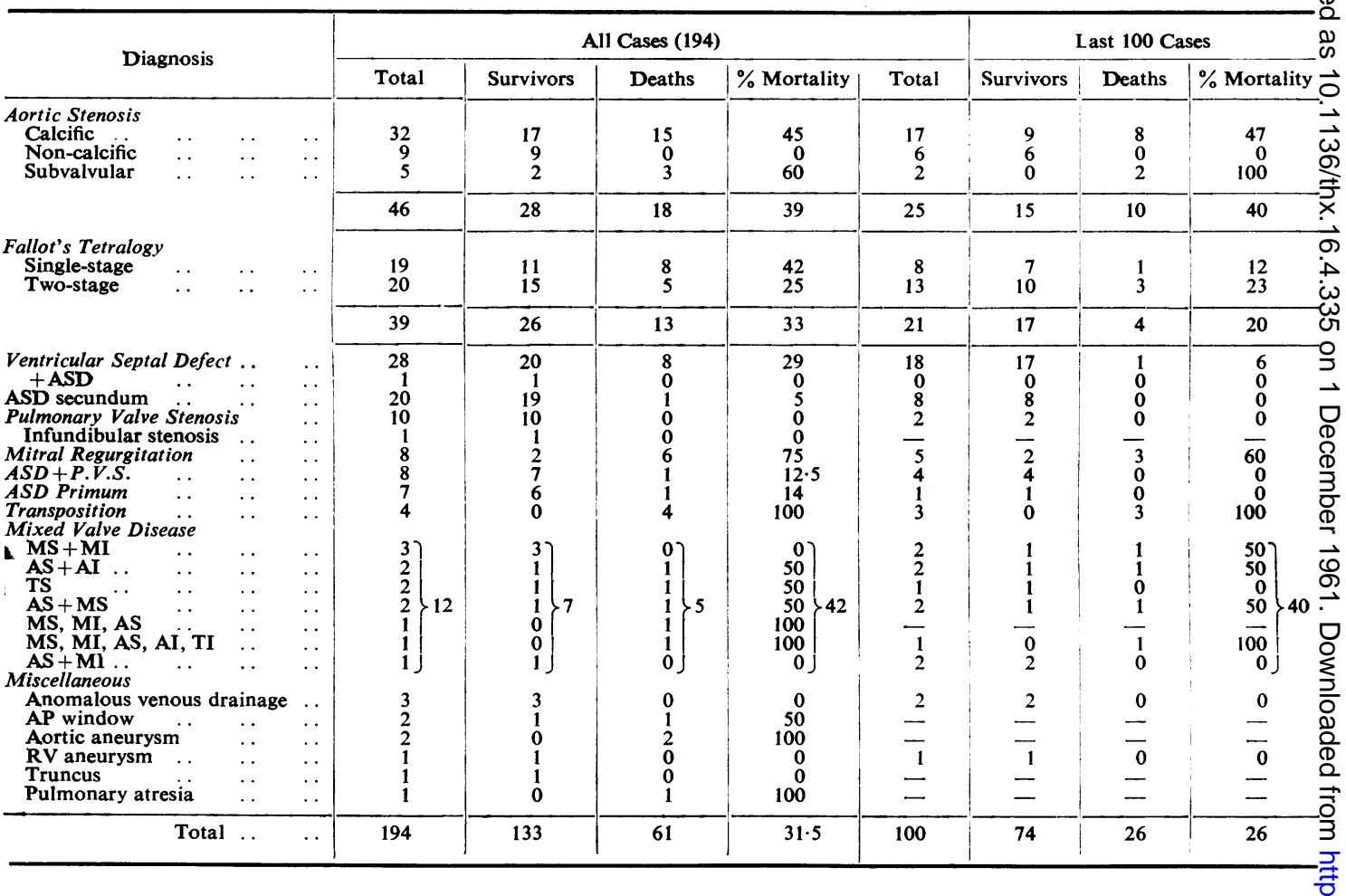

TABLE II

SEX DISTRIBUTION AND RANGE OF PERFUSION TIMES SIZE, WEIGHTS, AND AGES OF 109 MEN AND 84 WOMEN

Range of bypass time $\quad . . \quad 25-189 \mathrm{~min}$. (average $89.5 \mathrm{~min}$.)

", , size of patients .. $0.3-2 \cdot 12$ sq.m. (average 1.35 sq.m.)

, ,, weights of patients

," ," ages of patients .

$8-82 \mathrm{~kg}$. (average $49 \cdot 2 \mathrm{~kg}$.)

$3 \mathrm{mth} .-56 \mathrm{yr}$. (average $22.5 \mathrm{yr}$.)

new tubing was not excluded. This as a hazard has been pointed out by Keith, Ginn, Williams, and Campbell (1961).

Congulation.-Bleeding post-operatively has been a severe problem in some cases. One patient needed 10 litres of blood before stability occurred and at least one patient bled to death in spite of replacement with fresh blood, fibrinogen, calcium chloride and calcium gluconate, vitamin $K$, and hydrocortisone. Necropsy failed to reveal a surgical cause of the haemorrhage as do most cases reoperated on. One patient with aortic stenosis had a leak in the aortic suture line, but usually nothing is found but widespread oozing from all surfaces. A recent article by Bloom (1961) notes a fall in platelets and fibrinogen and an increase in fibrinolysis, while unneutralized heparin was noted in six out of seven of his으 cases studied. He goes on to comment on a lag period during which euglobulin lysis times are음 prolonged. Unneutralized heparin as a cause of bleeding may therefore be succeeded by haemorrhage due to fibrinolysis. At present $2 \mathrm{mg}$. of 2 "polybrene" (hexadimethrine bromide) is used to응 neutralize each milligram of heparin administered, $>$ after making due allowance for blood transfused으․ from the pump. If clotting is occurring beforen closure it is reasonable to accept that heparin has. been neutralized. The "rebound" bleeding 0 observed with protamine has not been noticed with " polybrene."

In one case pyrogenic activity was sought, bute no pyrogens were isolated by the Medical Research Council Temperature Control Unit at ${ }^{+}$ Oxford.

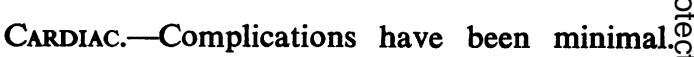
Heart block, occurring at operation for which $\mathbb{\Phi}_{\triangle}$ indwelling pacemaker electrodes have been inserted, has reverted to normal rhythm after a 
few days. In one patient it has been permanent and in one patient sinus rhythm returned a month after leaving hospital. Transient arrhythmias have occurred, e.g., paroxysmal atrial tachycardia, but these respond quickly to digitalis. Occasionally digitalis intoxication has been a problem due to dehydration or electrolyte imbalance, but recognition is usually prompt as all these patients are nursed in a recovery ward with constant attention.

Metabolic.-In patients who have survived, acidosis has not been a problem. Clearly a failing circulation allows a progressive metabolic acidosis which heralds the onset of death. Although sodium bicarbonate $\left(7 \frac{1}{2} \%\right)$ was given intravenously to three patients with severe acidosis it is not thought to have influenced the fatal outcome. Mild states of acidosis respond quickly to sodium bicarbonate and relief of carbon dioxide retention. If the heart restarts well and takes over the circulation at an adequate blood pressure it is unusual for acidosis to be a problem. A poor perfusion doubtless initiates or worsens a pre-existing acidosis, as in cases of Fallot's tetralogy, but if perfusion is adequate and normal haemodynamics are restored acidosis is rare.

Respiratory DePression.-This has occurred in several patients and has been associated with protracted hypotension, cardiac failure, haemorrhage, or heart block. It has become our policy to perform tracheostomy early and to ventilate the patient with a Barnet respirator after losing two patients who had chest complications and in whom the need for respiratory assistance was not recognized. The patients are ventilated at a flow compatible with good oxygenation and relief of carbon dioxide retention rather than by calculations from a nomogram referring to individuals with normal lungs. Regular observations of $p \mathbf{H}$, $\mathrm{PCO}_{2}$, plasma bicarbonate, and arterial oxygen saturation are necessary and there should be no hurry to wean the patient from the respirator until cardiac and pulmonary conditions have been stable for several days.

HyPOTHERMia.-There have been no complications attributable to the hypothermic state.

\section{SUMmaRY}

The diagnoses and results of treatment of 194 cases of surgical cardiac disease treated by open heart surgery are reviewed.

The complications of hypothermic perfusion are briefly noted.

I wish to thank Sir Russell Brock, Mr. Donald Ross, and Mr. Robert Brain for permission to quote their cases. Mrs. E. Esson has given extensive secretarial help.

\section{REFERENCES}

Baer, D. M., and Osborn, J. J. (1960). Amer. J. clin. Path., 34, 442. Bloom, A. L. (1961). Brit. med. J., 2, 16.

Brock, R. C. (1948). Ibid., 1, 1121.

- (1959a). Editorial, Amer. J. Cardiol., 3, 1.

- (1959b). Guy's Hosp. Rep., 108, 314.

Comroe, J. H. (1961). Tudor Edwards Memorial Lecture. Royal College of Physicians, London.

Keith, H. B., Ginn, E., Williams, G. R., and Campbell, G. S. (1961). J. thor. cardiovasc. Surg., 41, 404.

Molloy, P. J., and Lindfield, R. I. (1961). Thorax, 16, 325. 